\title{
FLORAÇÃO DE PESSEGUEIROS E NECTARINEIRAS NO PLANALTO MÉDIO DO RIO GRANDE DO SUL, INFLUENCIADA PELAS CONDIÇÕES METEOROLÓGICAS ${ }^{1}$
}

\author{
FLOWERING OF PEACH AND NECTARINE TREES IN THE MEDIAN \\ PLANES OF RIO GRANDE DO SUL INFLUENCED BY \\ WEATHER CONDITIONS
}

\author{
Alexandre Augusto Nienow ${ }^{2}$ Luiz Gustavo Floss $^{3}$
}

\section{RESUMO}

\begin{abstract}
A floração e brotação de cultivares e seleções de pessegueiros e nectarineiras foi estudada com a finalidade de auxiliar na indicação dos mais promissores para a região do Planalto Médio do Rio Grande do Sul. Foram avaliadas as safras 1997/98, 1998/99 e 1999/00, estudando-se doze cultivares e nove seleções de pessegueiro, e dois cultivares e uma seleção de nectarineira, com exigências em acúmulo de frio menor que $7,2^{\circ} \mathrm{C}$ entre 150 e 400 horas. A coleção, com três plantas por cultivar/seleção, plantadas no espaçamento $6 \times 3 \mathrm{~m}$ e conduzidas no sistema de vaso aberto, sem irrigação, encontrava-se, em 1997, no sexto ciclo vegetativo. Verificou-se que a redução da ocorrência de baixas temperaturas a partir do final de junho e em julho, proporcionou, em todas as safras, condições térmicas favoráveis à antecipação da floração dos pessegueiros $e$ nectarineiras em até 15 dias, em relação a anos normais. $O$ início do florescimento ocorreu, na maioria dos genótipos, durante o mês de julho e início de agosto.
\end{abstract}

Palavras-chave: Prunus persica, pêssego, nectarina, florescimento, fenologia.

\section{SUMMARY}

Studies about blooming and budding of nectarine and peach trees and selections have been carried out at the Universidade de Passo Fundo, Passo Fundo, to identify materials that are better adapted to Planalto Médio region of Rio Grande do Sul State, Brazil. Through experiments carried out in the growing seasons of 1997/98, 1998/99 and 1999/00, twelve cultivars and nine peach selections, two cultivars and one nectarine selection were studied, all with required aculate temperature lower than $7,2^{\circ} \mathrm{C}$, ranging from 150 and 400 hours.
The fruit tree collections included three plants of each cultivar, which were grown at $6 \times 3 \mathrm{~m}$ from each other and conducted according to an open vase shape, without irrigation. In 1997, plants were at the beginning of the sixth growth cycle. The decrease of the occurrence of low temperatures from late June and in July, in all growing seasons, resulted in earlier blooming (up to 15 days). For most cultivars and selections flowering began in July and early August.

Key words: Prunus persica, peach, nectarine, cultivars, phenology.

\section{INTRODUÇÃO}

De acordo com Weinberger, citado por HERTER $\boldsymbol{e t}$ al. (1998), para a formação das gemas floríferas e vegetativas do pessegueiro e a quebra da dormência, é necessário que as plantas sejam submetidas a um período de baixas temperaturas, quando ocorrem transformações hormonais, convencionalmente medidas pelo número de horas de frio inferiores ou iguais a $7,2^{\circ} \mathrm{C}$. Conforme SACHS \& HERTER (1984), a gema florífera apenas se completa durante os meses de inverno, quando ocorre o desenvolvimento do ovário e a formação do pólen. Segundo MOTA (1992), o acúmulo médio de horas com temperaturas menores que $7,2^{\circ} \mathrm{C}$ na região de Passo Fundo situa-se entre 375 (maio a agosto) e 420 horas (maio a setembro). Segundo

\footnotetext{
${ }^{1}$ Trabalho apresentado no XVI Congresso de Fruticultura, Fortaleza, 2000.

${ }^{2}$ Engenheiro Agrônomo, Doutor, Professor de Fruticultura, Faculdade de Agronomia e Medicina Veterinária, Universidade de Passo Fundo, CP 611, 99001-970, Passo Fundo, RS. E-mail: alexandre@upf.tche.br. Autor para correspondência.

${ }^{3}$ EngenheiroAgrônomo, ex-aluno da FAMV-UPF e ex-bolsista PIBIC - Universidade de Passo Fundo.
} 
CUNHA (1997), no município de Passo Fundo, considerando o período de 1979 a 1992, a média anual de horas de frio menor que $7^{\circ} \mathrm{C}$ foi de 422 horas, variando de 214 a 554 horas.

Estudos demostraram que temperaturas acima de $7,2^{\circ} \mathrm{C}$ também auxiliam na rompimento da dormência, principalmente de cultivares de menor exigência em frio. Há evidências de que altas temperaturas, ocorrendo intermitentemente durante o período de dormência, têm efeito negativo, pois não só diminuem o efeito cumulativo como tendem a neutralizar o frio já ocorrido (PETRI, 1986).

Há três teorias que procuram explicar a saída de dormência das plantas: a redução da concentração de inibidores de crescimento; o aumento da concentração de promotores de crescimento; e, o balanceamento entre inibidores e promotores. Para AUDUS (1972), a quebra da dormência e os processos internos envolvidos estão associados a mudanças nos níveis não somente dos hormônios promotores de crescimento (giberelinas, auxinas e citocininas), mas, principalmente, dos inibidores. Tem sido verificado que o nível dos inibidores de crescimento diminui à medida que a necessidade de frio é satisfeita. Assim, as plantas mais exigentes em frio apresentam uma concentração de inibidores mais alta (PETRI, 1986). Segundo BROWEN \& DERICKSON (1978), a concentração de inibidores em pessegueiros mais exigentes em frio pode chegar a $2,5 \mu \mathrm{g} \cdot \mathrm{g}^{-1}$ de tecido, enquanto os cultivares desenvolvidos para regiões subtropicais apresentam cerca de $0,75 \mu \mathrm{g} \cdot \mathrm{g}^{-1}$ de tecido.

O fator genético é o mais importante na definição da necessidade de frio de cada cultivar para quebrar a dormência. Quando a exigência não é satisfeita, há uma série de sintomas e prejuízos, como: baixa porcentagem de brotação de gemas laterais e/ou retardamento da brotação; relativa antecipação da brotação das gemas terminais; forte dominância apical, causando inibição do crescimento das brotações laterais; floração desuniforme por período prolongado; e as flores podem apresentar pistilo ou pólen defeituosos, reduzindo, quando em grande número, a frutificação efetiva. $\mathrm{O}$ baixo enfolhamento reduz a fotossíntese, afeta a frutificação, a qualidade dos frutos e as reservas de carboidratos da planta no início da brotação (Skinner, citado por CAMELATTO, 1990).

Além do acúmulo de frio durante a endodormência, tem sido verificado que, para iniciar o florescimento, cada cultivar de pessegueiro necessita de um número de unidades de calor após a endodormência (RASEIRA \& MOORE, 1987; CITADIN, 1999), período denominado de ecodormência. Para explicar como se dá o processo, segundo CITADIN (1999), várias hipóteses são levantadas na literatura, se conclui que o acúmulo de frio é o principal fator responsável na regulação do tempo para iniciar a floração, pois a diminuição da necessidade de calor se dava à medida que a planta era submetida a um maior número de horas de frio abaixo de 7,2 C. Para WERNER et al. (1988), as variações nas datas de floração são devidas às diferenças nas temperaturas bases para o acúmulo de calor e não ao requerimento de frio.

SPIEGEL-ROY \& ALSTON (1979), estudando genótipos de pereira, concluíram que cultivares de floração precoce tendem a ter um baixo requerimento de frio e calor, e vice-versa. Já os cultivares de floração intermediária não apresentaram forte relação entre necessidade de frio e calor. Por sua vez, Scorza \& Okie, citado por CITADIN (1999), verificaram que alguns cultivares de pessegueiro de floração tardia têm baixo requerimento em frio. Esta observação suporta a hipótese da existência de diferenças genotípicas para a exigência em acúmulo de determinada soma térmica para a ocorrência da floração.

Este trabalho estudou o comportamento da floração de cultivares e seleções de pessegueiro e nectarineira, produtores de frutos para consumo in natura, sob a influência das condições meteorológicas da região do Planalto Médio do Rio Grande do Sul.

\section{MATERIAL E MÉTODOS}

A coleção de pessegueiros e nectarineiras encontra-se instalada no Centro de Extensão e Pesquisa Agronômica (Cepagro) da Faculdade de Agronomia e Medicina Veterinária da Universidade de Passo Fundo, localizado nas imediações da cidade de Passo Fundo (latitude $28^{\circ} 15^{\prime} 41^{\prime}$ 'S e longitude $52^{\circ} 24^{\prime} 45^{\prime}$ ' $\mathrm{O}$, a $709 \mathrm{~m}$ de altitude).

$\mathrm{O}$ solo da área experimental pertence à unidade de mapeamento Passo Fundo, caracterizado como Latossolo Vermelho Distrófico típico. Os dados meteorológicos foram obtidos na EmbrapaTrigo, localizada a 1000m da coleção (Tabela 1).

Foram estudados doze cultivares de pessegueiro, alguns com conhecido requerimento de horas de frio (HF) menor ou igual a $7,2^{\circ} \mathrm{C}$ [Premier e Jóia (150HF), Peach 16-33 e Sulina (200HF), Chimarrita e Eldorado (250HF), Marli (300HF), Guaiaca (300-400HF), Vila Nova (400HF), Carmim, Purpúreo e Xavante] e nove seleções (Cascata 415, 
Tabela 1 - Médias meteorológicas ocorridas nos anos de 1994, 1997, 1998 e 1999 (Embrapa-Trigo, 2000 - Informe verbal), normais climatológicas (1961-1990) e média de horas de frio (1979-1992) ocorridas no município de Passo Fundo - RS (CUNHA, 1997)

\begin{tabular}{|c|c|c|c|c|c|c|c|c|c|c|c|c|}
\hline \multirow[b]{2}{*}{ Anos } & \multicolumn{12}{|c|}{ Temperatura média $\left({ }^{\circ} \mathrm{C}\right)$} \\
\hline & Jan & $\mathrm{Fev}$ & Mar & Abr & Mai & Jun & Jul & Ago & Set & Out & Nov & Dez \\
\hline 1994 & 21,9 & 21,2 & 20,4 & 17,7 & 16,7 & 12,4 & 13,5 & 14,6 & 16,5 & 18,8 & 19,2 & 23,5 \\
\hline 1997 & 23,1 & 22,1 & 20,1 & 17,6 & 15,0 & 12,5 & 14,6 & 15,3 & 16,2 & 17,5 & 20,3 & 22,6 \\
\hline 1998 & 22,6 & 21,1 & 19,6 & 17,1 & 14,2 & 12,3 & 13,8 & 14,1 & 14,3 & 18,1 & 20,1 & 21,1 \\
\hline 1999 & 22,2 & 21,4 & 22,2 & 17,0 & 13,3 & 12,0 & 11,8 & 14,0 & 16,1 & 16,2 & 18,5 & 21,9 \\
\hline \multirow[t]{2}{*}{ Normais } & 22,1 & 21,9 & 20,6 & 17,6 & 14,3 & 12,7 & 12,8 & 14,0 & 14,8 & 17,7 & 19,8 & 21,5 \\
\hline & \multicolumn{12}{|c|}{ Temperatura média das máximas $\left({ }^{\circ} \mathrm{C}\right)$} \\
\hline Anos & Jan & Fev & Mar & Abr & Mai & Jun & Jul & Ago & Set & Out & Nov & $\overline{\text { Dez }}$ \\
\hline 1994 & 28,1 & 26,1 & 25,8 & 23,9 & 21,9 & 17,9 & 18,8 & 21,5 & 23,1 & 24,2 & 25,1 & 29,8 \\
\hline 1997 & 29,3 & 27,5 & 27,1 & 25,0 & 21,7 & 17,5 & 20,3 & 21,1 & 21,9 & 22,3 & 26,1 & 28,7 \\
\hline 1998 & 28,5 & 26,4 & 24,9 & 22,2 & 19,9 & 18,3 & 19,1 & 18,7 & 19,0 & 24,2 & 27,1 & 27,3 \\
\hline 1999 & 28,4 & 27,4 & 28,7 & 22,7 & 19,0 & 17,5 & 16,7 & 21,1 & 22,3 & 21,4 & 25,1 & 28,6 \\
\hline \multirow[t]{2}{*}{ Normais } & 28,3 & 28,0 & 26,7 & 23,7 & 20,7 & 18,4 & 18,5 & 19,9 & 21,2 & 23,8 & 26,0 & 27,8 \\
\hline & \multicolumn{12}{|c|}{ Temperatura média das mínimas $\left({ }^{\circ} \mathrm{C}\right)$} \\
\hline Anos & Jan & Fev & Mar & Abr & Mai & Jun & Jul & Ago & Set & Out & Nov & Dez \\
\hline 1994 & 16,8 & 17,9 & 15,1 & 13,3 & 13,4 & 8,8 & 9,8 & 9,9 & 11,9 & 14,9 & 14,5 & 18,5 \\
\hline 1997 & 18,4 & 18,6 & 15,1 & 12,2 & 10,6 & 9,3 & 10,7 & 10,9 & 11,7 & 13,8 & 16,1 & 17,8 \\
\hline 1998 & 18,5 & 17,4 & 16,0 & 13,7 & 10,8 & 8,5 & 10,5 & 11,2 & 10,7 & 13,8 & 14,4 & 16,2 \\
\hline 1999 & 17,6 & 17,1 & 17,9 & 13,4 & 9,4 & 8,6 & 8,2 & 8,8 & 11,5 & 12,2 & 13,1 & 17,0 \\
\hline Normais & 17,5 & 17,5 & 16,3 & 13,5 & 10,9 & 8,9 & 8,9 & 9,9 & 11,0 & 12,9 & 14,8 & 16,5 \\
\hline \multirow{3}{*}{ Anos } & \multicolumn{12}{|c|}{ Horas de frio $\left(<7^{\circ} \mathrm{C}\right)$} \\
\hline & \multirow{2}{*}{\multicolumn{2}{|c|}{$\begin{array}{c}\text { Total } \\
(\text { Mar - Jul) }\end{array}$}} & \multicolumn{8}{|c|}{ Meses } & \multirow{2}{*}{\multicolumn{2}{|c|}{$\begin{array}{c}\text { Total } \\
\text { (Mar-Ago) }\end{array}$}} \\
\hline & & & Mar & Abr & Mai & Jun & Jul & Ago & Set & Out & & \\
\hline 1994 & \multicolumn{2}{|c|}{213,2} & 0 & 0 & 3,8 & 89,0 & 120,4 & 95,4 & 46,3 & 0 & \multicolumn{2}{|c|}{308,6} \\
\hline 1997 & \multicolumn{2}{|c|}{182,1} & 0 & 10,8 & 50,6 & 100,4 & 20,3 & 16,8 & 22,1 & 2 & \multicolumn{2}{|c|}{198,9} \\
\hline 1998 & \multicolumn{2}{|c|}{132,3} & 3,8 & 0,5 & 5,3 & 54,1 & 68,6 & 15,3 & 10,8 & 0 & \multicolumn{2}{|c|}{147,6} \\
\hline 1999 & \multicolumn{2}{|c|}{224,1} & 0 & 34,5 & 56,0 & 64,8 & 68,8 & 107,5 & 4,0 & 9,5 & \multicolumn{2}{|c|}{331,6} \\
\hline \multirow[t]{2}{*}{ Normais } & & & 1,0 & 5,0 & 51,0 & 116,0 & 123,0 & 69,0 & 47,0 & 10,0 & & \\
\hline & \multicolumn{12}{|c|}{ Chuvas (mm) } \\
\hline Anos & Jan & $\mathrm{Fev}$ & Mar & Abr & Mai & Jun & Jul & Ago & Set & Out & Nov & $\overline{\text { Dez }}$ \\
\hline 1994 & 55,2 & 333,6 & 69,8 & 193,6 & 152,2 & 198,8 & 243,0 & 46,0 & 161,7 & 308,7 & 138,1 & 235,2 \\
\hline 1997 & 156,3 & 129,8 & 33,2 & 69,5 & 103,7 & 114,4 & 115,8 & 257,5 & 152,0 & 550,4 & 339,9 & 235,5 \\
\hline 1998 & 231,0 & 357,6 & 229,9 & 342,2 & 201,0 & 82,7 & 191,0 & 257,4 & 204,2 & 118,9 & 68,5 & 122,5 \\
\hline 1999 & 125,3 & 114,4 & 65,4 & 188,3 & 108,7 & 94,3 & 176,8 & 19,4 & 149,5 & 177,1 & 118,6 & 131,1 \\
\hline Normais & 143,4 & 148,3 & 121,3 & 118,2 & 131,3 & 129,4 & 153,4 & 165,7 & 206,8 & 167,1 & 141,4 & 161,5 \\
\hline
\end{tabular}

Cascata 643, Cascata 647, Cascata 655, Cascata 672, Taquari 122, Taquari 126, Taquari 192, Taquari 198); dois cultivares de nectarineira (Linda e Sunlite) e uma seleção (Necta 146). Dentre estes, são cultivados no Rio Grande do Sul, em maior ou menor escala, os seguintes cultivares: Chimarrita, Eldorado, Guaiaca, Marli, Peach 16-33, Premier, Sulina e Vila Nova.

Para permitir a incorporação de novos materiais genéticos, os cultivares foram dispostos sequiencialmente no campo, representados por três ou cinco plantas. $\mathrm{O}$ espaçamento adotado entre plantas foi de $6 \times 3 \mathrm{~m}$, conduzidas no sistema de vaso aberto, sem irrigação. Em 1997, quando do início das observações, as plantas encontravam-se no sexto ciclo vegetativo.

O comportamento da floração e brotação foi determinado, em três safras (1997/98, 1998/99 e 1999/00), através da coleta dos seguintes dados: data de início da floração (5\% das gemas floríferas abertas) e final da floração (menos de $2 \%$ das gemas por abrir); duração da floração; e data de início da brotação. 


\section{RESULTADOS E DISCUSSÃO}

A época de floração das seleções e cultivares variou dentro de cada safra e entre as três safras estudadas (Figuras 1, 2 e 3), contudo, a sequiência dos mais precoces aos mais tardios foi, em geral, mantido. As variações da época de floração decorrem das diferenças individuais em necessidade de horas de frio para o rompimento da dormência (Weinberger, citado por HERTER $\boldsymbol{e t}$ al., 1998) e, possivelmente, de calor para romperem a dormência (RASEIRA \& MOORE, 1987; CITADIN, 1999). A duração média da floração de cada cultivar ou seleção variou de 12 a 29 dias, influenciada não apenas pelo fator genético, mas também pelas condições meteorológicas (temperaturas e chuvas) durante a floração.

Nas três safras analisadas, o início da floração ocorreu durante o mês de julho e início de agosto, entre 5 de julho e 9 de agosto. Apenas na safra 1998/99 a antecipação dos cvs. Sulina e Premier foi mais acentuada, iniciando a floração em 20 de junho e 24 de junho, respectivamente (Figuras $1,2$ e 3$)$.

Comparativamente com a safra 1994/95, verificou-se que houve, nas safras 1997/98, 1999/00 e, mais acentuadamente, na safra 1998/99 (Figura 4), antecipação do período de floração, principalmente por parte dos genótipos menos exigentes em frio. Em 1994, as temperaturas permaneceram baixas durante os meses de junho e julho, até meados de agosto (Tabela 1), meses em que ocorreu o maior número de horas de frio abaixo de $7^{\circ} \mathrm{C}$, totalizando, até final de agosto, 308,6 horas de frio. Já nos demais anos estudados, houve elevação da temperatura a partir de final de junho/início de julho, cujas médias diárias permaneceram acima de $10^{\circ} \mathrm{C}$.

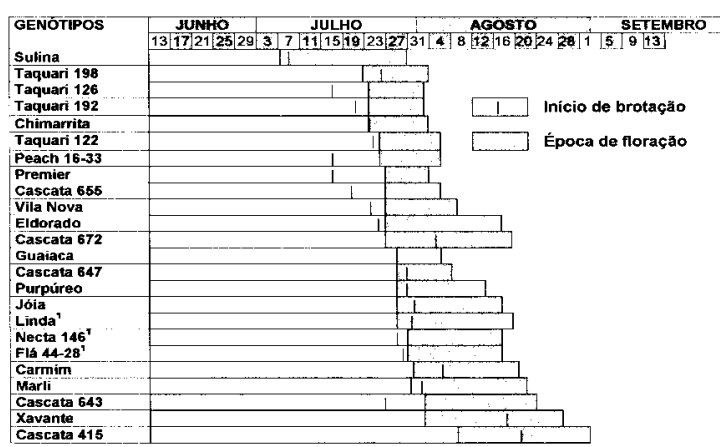

Figura 1 - Início da brotação e época de floração de cultivares e seleções de pessegueiro e nectarineira $\left(^{1}\right)$ em Passo Fundo, RS - safra 1997/98.

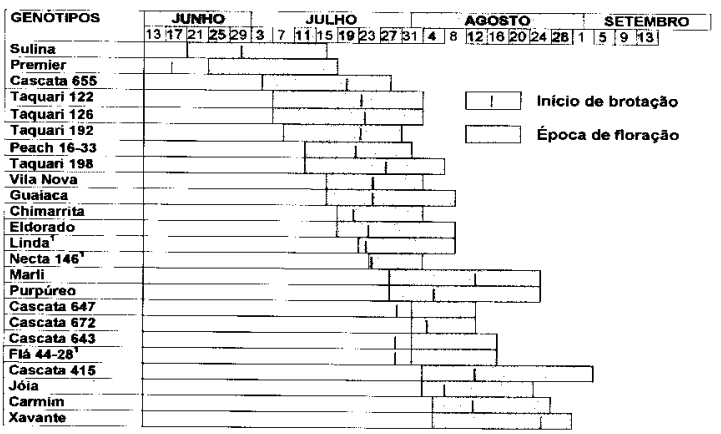

Figura 2 - Início da brotação e época de floração de cultivares e seleções de pessegueiro e nectarineira $\left({ }^{1}\right)$ em Passo Fundo, RS - safra 1998/99.

Nos anos de 1997 e 1998, em julho, as temperaturas média, média das máximas e das mínimas, foram superiores às normais registradas (Tabela 1). A menor ocorrência de frio, nestes anos, evidencia-se pelo baixo acúmulo de horas de frio registradas até julho (182,1 e 132,3 horas, respectivamente), mantendo-se praticamente inalterado ao considerar também agosto $(198,9$ e 147,6 horas, respectivamente) (Tabela 1), abaixo do normal para Passo Fundo, que é, em média, de 296 horas (março - julho) e 365 horas (março - agosto) (CUNHA, 1997).

A maior antecipação da floração em 1998, em relação aos demais anos, pode ser atribuída à menor ocorrência de baixas temperaturas desde maio (Tabela 1), propiciando condições térmicas de indução precoce da floração dos genótipos menos exigentes em frio.

Na safra 1998/99, a quantidade de horas de frio elevou-se para 224,1 (março - julho) e 331,6 (março - agosto), entretanto, justifica-se a

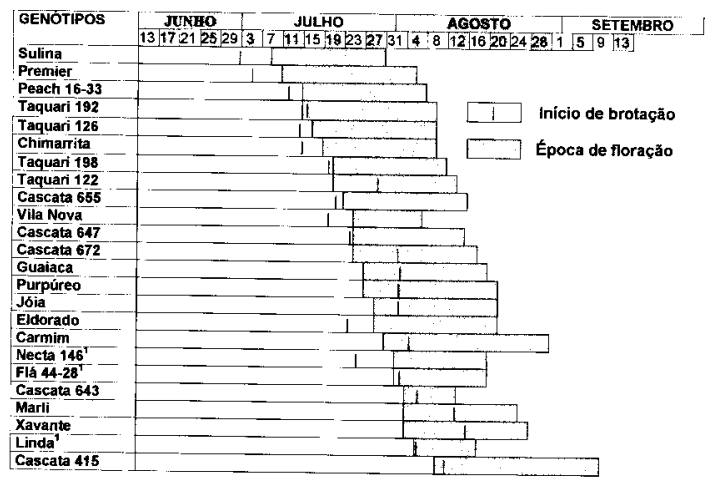

Figura 3 - Início da brotação e época de floração de cultivares e seleções de pessegueiro e nectarineira $\left(^{1}\right)$ em Passo Fundo, RS - safra 1999/00. 


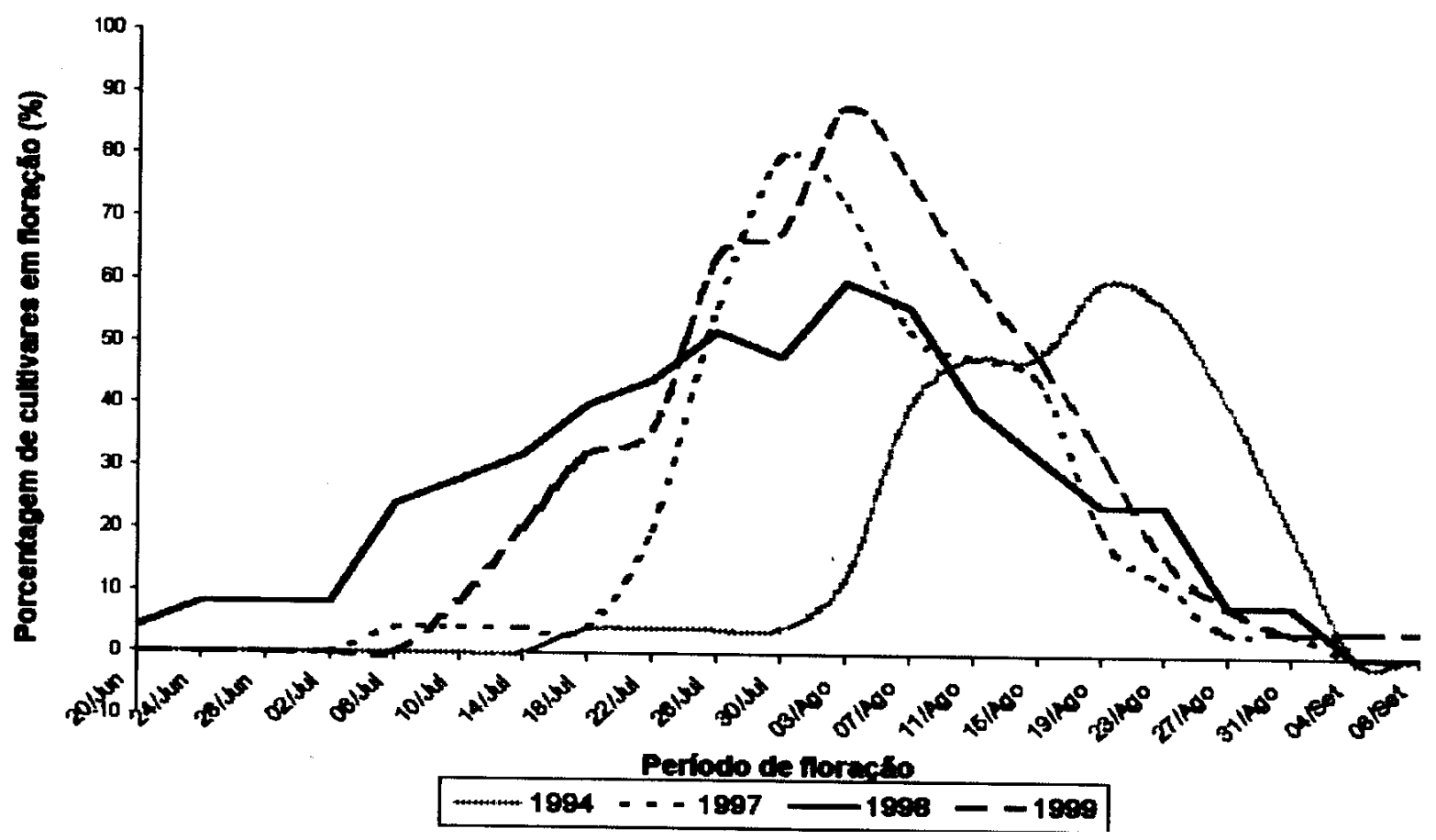

Figura 4 - Comparativo da porcentagem acumulada de cultivares e seleções de pessegueiro e nectarineira em floração nas safras 1994/95, 1997/98, 1998/99 e 1999/00, Passo Fundo, RS.

antecipação da floração também pela menor ocorrência de baixas temperaturas em final de junho e em julho. Se comparado com as normais, o número de horas frio ocorrido em junho e julho foi $44 \%$ inferior (Tabela 1). No mês de agosto, a quantidade de frio foi significativa, mas não suficiente para interromper a floração. A ocorrência de uma forte geada tardia, em 13 de agosto $\left(-4^{\circ} \mathrm{C}\right)$, afetou a produção, uma vez que a maioria dos genótipos estavam em plena floração ou haviam concluído.

Conforme observaram alguns autores (RASEIRA \& MOORE, 1987; CITADIN, 1999), além do acúmulo de frio durante a endodormência para iniciar o florescimento, os pessegueiros necessitam de um número de unidades de calor, condição esta que foi propiciada mais precocemente nas safras estudadas.

A dispersão das datas de início da floração diferiu em cada safra (Figuras 1, 2 e 3), tendo sido maior na safra 1998/99. Na safra 1997/98, o início da floração, para a maioria dos cultivares e seleções, ocorreu em um curto período, entre 20 de julho e 2 de agosto (14 dias), diferentemente das demais safras. $O$ fato pode ser atribuído ao estresse hídrico, ocorrido em março e abril de 1997, que somou $102,7 \mathrm{~mm}$ de chuva, contra $239,5 \mathrm{~mm}$ em anos normais (Tabela 1), o que teria propiciado maior velocidade na diferenciação das gemas floríferas, conforme observou Garza, citado por LEZAMA (1990), e exercido um efeito substitutivo ao frio, permitindo que, ao ocorrerem condições meteorológicas favoráveis (calor), o início da floração tenha se dado de forma relativamente uniforme. A antecipação da floração pode ser comprovada se comparada aos resultados de outros autores, como SIMONETTO et al. (1995), em Veranópolis - RS, e NIENOW \& LICODIEDOFF (1996), em Passo Fundo, RS. Assim, o cv. Premier (150HF) antecipou cerca de 15 dias a floração; o cv. Chimarrita $(200 \mathrm{HF})$ entre 9 e 15 dias; e o cv. Marli, mais exigente em frio (300HF), em até 10 dias.

$\mathrm{O}$ início da brotação, em relação à data de início da floração, variou em cada safra. Nas safras 1997/98 e 1999/00, os materiais com menor requerimento em frio iniciaram a brotação, de modo geral, antes do início da floração. Ao contrário, na safra 1998, quando a precocidade da floração foi mais acentuada, a brotação ocorreu próximo à plena floração (Figuras 1, 2 e 3). Em todas as safras, nos cultivares considerados de meia - estação e tardios, a brotação normalmente iniciou durante o período de floração. 
A demasiada antecipação da brotação, em relação ao início da floração, deve ser vista com cuidado, uma vez que pode trazer prejuízos à frutificação, provavelmente pela competição por nutrientes entre o crescimento vegetativo e as gemas floríferas, conforme observou NIENOW (1997).

\section{CONCLUSÕES}

A redução da ocorrência de baixas temperaturas na região do Planalto Médio do Rio Grande do Sul a partir do final de junho e em julho, proporcionou, em todas as safras avaliadas (1997/98, 1998/99 e 1999/00), condições térmicas favoráveis à antecipação da floração dos pessegueiros e nectarineiras em até 15 dias, em relação a anos normais.

Os fatores climáticos interferiram na dispersão das datas de início de floração e brotação dos cultivares e seleções em cada safra.

\section{REFERÊNCIAS BIBLIOGRÁFICAS}

AUDUS, L.J. Plant growth substances. 3.ed. Leonor Hill Books, 1972. Natural plant growth inhibitors: p.155-77.

BROWEN, H.H., DERICKSON, G.W. Relationship of endogenous flower but abscisic acid to peach chilling requeriments, blomm dates, and applied gibberelic acid. HortScience, Alexandria, v.13, n.6, p.694-96, 1978.

CAMELATTO, D. Dormência em fruteiras de clima temperado. Horti Sul, Pelotas, v.1, n.3, p.12-17, 1990.

CITADIN, I. Necessidade de calor para antese e brotação em pessegueiro [Prunus persica (L.) Batsch]. Pelotas, 1999, 74p. Dissertação (Mestrado em Fruticultura de Clima Temperado) - Faculdade de Agronomia Eliseu Maciel, Universidade Federal de Pelotas, 1999.

CUNHA, G.R. da. Meteorologia: fatos \& mitos. Passo Fundo : Embrapa-CNPT, 1997. 268p.

HERTER, F.G., SACHS, S., FLORES, C.A. Condições edafoclimáticas para instalação do pomar. In: MEDEIROS, C.A.B., RASEIRA, M. do C.B. (Eds.). A cultura do pessegueiro. Brasília : Embrapa-SPI; Pelotas:EmbrapaCPACT, 1998. p.20-28.
LEZAMA, E.V. Produccion forzada en tres cultivares de durazno (Prunus persica (L) Batsch) bajo un sistema intensivo de produccion. Montecillo, México, 1990, 102p. Tesis (Maestro en Ciências, Especialista en Fruticultura) Colegio de Postgraduados, Institución de Enseñanza e Investigación en Ciencias Agrícolas, 1990.

MOTA, F.S. da. Mapeamento de horas de frio para indicação do cultivo de fruteiras criófilas no Rio Grande do Sul. Revista Brasileira de Fruticultura, Cruz das Almas, v.14, n.1, p.83$88,1992$.

NIENOW, A.A. Comportamento morfológico, fenológico e produtivo de cultivares de pessegueiro [Prunus persica (L.) Batsch], submetidos à poda de renovação após a colheita, na região de Jaboticabal, SP. Jaboticabal, 1997. 171p. Tese (Doutorado em Produção Vegetal) - Curso de Pós-graduação em Agronomia, Faculdade de Ciências Agrárias e Veterinárias, Universidade Estadual Paulista, 1997.

NIENOW, A.A., LICODIEDOFF, M.C. Comportamento fenológico e produtivo de cultivares de pessegueiro e nectarineira no Planalto Médio do Rio Grande do Sul. Revista Brasileira de Fruticultura, Cruz das Almas, v.18, n.2, p.201-208, 1996.

PETRI, J.L. Dormência da macieira. In: EMPASC. Manual da cultura da macieira. Florianópolis : Empasc, 1986. p.163201.

RASEIRA, M.C.B., MOORE, J.N. Time of flower bud initiation in peach cultivars differing in chilling requirement. Hortscience, Alexandria, v.22, n.2, p.216-218, 1987.

SIMONETTO, P.R., GRELLMANN, E.O., SCHMIDT, E. Comportamento de cultivares de pêssego para mesa na região da Serra do nordeste do Rio Grande do Sul. Porto Alegre : Fepagro, 1995. 20p. (Circular Técnica, 8).

SACHS, S., HERTER, F.G. Localização do pomar. In: SACHS, S., et al. A cultura do pessegueiro. Pelotas : EmbrapaCNPFT, 1984. p.13-19. (Circular técnica, 10)

SPIEGEL-ROY, P., ALSTON, F.H. Chilling and post-dormant heat requirement as selection criteria for late-flowering pears. Journal of Horticultural Science, Ashford kent, v.54, n.2, p.115-120, 1979.

WERNER, D.J., MOWREY, B.D., YOUNG, E. Chilling requirement and post-rest heat acumulation as related to difference in time of bloom between peach and western sand cherry. Journal of the American Society for Horticultural Science, Mount Vernon, v.113, n.5, p.775-778, 1988. 